\title{
A EDUCAÇÃO PARA O TRÂNSITO COMO INSTRUMENTO PARA A EDUCAÇÃO AMBIENTAL
}

\author{
Josefina Giacomini Kiefer ${ }^{1}$
}

\section{RESUMO}

Este estudo expõe a experiência dos programas de educação para o trânsito, desenvolvidos pela Companhia de Engenharia de Tráfego de São Paulo, ações educativas com relação a meio ambiente e qualidade de vida. Foram consultados documentos internos à área de educação para o trânsito, profissionais envolvidos no desenvolvimento destes programas e o site institucional da CET. Estes programas acontecem em escolas e instituições de educação não-formal, com crianças e adolescentes. A cidade de São Paulo, hoje a maior cidade da América Latina, a segunda do mundo em população e uma das cinco maiores áreas metropolitanas do mundo. Possui uma frota de 6,6 milhões de veículos automotores e uma população de 11 milhões de habitantes, 94\% da população em área urbana e 6\% em área rural, em uma área de $1.523 \mathrm{~km}$. Os órgãos responsáveis pela gestão do trânsito nos municípios, na cidade de São Paulo, a Companhia de Engenharia de Tráfego, promovem medidas para a melhoria das condições e modernização do trânsito da cidade, mas, as necessidades quanto à mobilidade segura e cuidado com o meio ambiente, não dependem apenas destes, mas de atitudes e posturas adotadas pelos cidadãos, moradores e usuários desta cidade.O aprendizado e a disseminação de saberes sobre educação para o trânsito e cidadania podem contribuir para a melhoria do convívio entre os atores do trânsito na cidade de São Paulo e torna-se poderoso veículo para a discussão e promoção da educação

\footnotetext{
${ }^{1}$ Mestrado em EAHC da Universidade Presbiteriana Mackenzie e Gestora de Educação de Trânsito da CET, SP. Rua Valson Lopes, 70 ap 73 T.1;finagk@yahoo.com.br.
} 
ambiental.São atendidos, anualmente, com estes programas de educação não-formal ,por volta de 200 mil pessoas.

Palavras chave: Agenda 21, Trânsito, Meio Ambiente

\section{INTRODUÇÃO}

O esvaziamento das áreas rurais e a superpopulação migrante para as grandes cidades fazem destes espaços, na atualidade, locais de alta concentração econômica, mas baixa qualidade ambiental.

Viver numa grande cidade significa conviver com a poluição do ar, congestionamentos, demanda excessiva aos serviços de saúde, violência, entre outros.

Segundo o IBGE (2009), a cidade de São Paulo é hoje a maior cidade da América Latina, a segunda do mundo em população e uma das cinco maiores áreas metropolitanas do mundo. Possui, atualmente, uma frota de 6,6 milhões de veículos automotores em circulação e uma população de 11 milhões de habitantes, $94 \%$ da população concentrados em área urbana e $6 \%$ em área rural, tudo isso disposto em uma área de $1.523 \mathrm{Km}^{2}$.

Dentre os problemas enfrentados pelos paulistanos, no dia-a-dia desta metrópole, estão àqueles relacionados à mobilidade e circulação pela cidade, além da poluição do ar. São fatores de aumento da poluição do ar: a grande quantidade de veículos em circulação, os congestionamentos que causam lentidão e provocam o aumento da emissão de poluentes pelo tempo em que o veículo encontra-se parado na via, a falta de regulagem de motores e controle sobre a qualidade dos combustíveis utilizado, entre outros. É no nosso século, no entanto, que o trânsito vai generalizar-se como problema urbano, à medida que as cidades crescem: a questão do trânsito faz parte da questão urbana de nossa época. Acidentes, congestionamentos, barulho, poluição parecem configurar um conjunto de condições adversas, que fazem com que o trânsito tenha uma imagem negativa, de caos, entre a maioria das pessoas que moram nas grandes cidades (VASCONCELOS, 1985, p. 08).

Equivocadamente, a ideia que temos sobre trânsito remete-nos aos problemas decorrentes de ações que prejudicam o trânsito, como o excesso de veículos que causa 
congestionamentos, mas trânsito não significa "congestionamento". Trânsito, enquanto definição do espaço de circulação urbano significa movimento, é o ir e vir de pessoas e veículos pela cidade.

Trânsito é o conjunto de deslocamentos diários de pessoas pelas calçadas e vias; é a movimentação geral de pedestres e de diferentes tipos de veículos. O trânsito ocorre em espaço público e reflete o movimento de múltiplos interesses atendendo às necessidades de trabalho, saúde, lazer e outros, muitas vezes conflitantes. Para garantir o equilíbrio entre esses interesses coletivos é que se estabelecem acordos sociais, sob a forma de regras, normas e sinais que, sistematizados formam as leis (TOLENTINO, 2006).

Parte da falta de mobilidade na cidade e os transtornos que causam a contaminação do ar da cidade pelos veículos automotores ocorrem exatamente pela "opção" do paulistano em utilizar meio de transporte particular ao invés do transporte coletivo. Digo "opção", entre aspas, pois muitos justificam esta escolha pela ausência de transporte coletivo, como ônibus, metrô, trem, em quantidade insuficiente para o atendimento de toda população; desconforto, em decorrência da má conservação da frota de coletivos, extensivo ao trem; a falta de regularidade quanto aos horários de chegada/saída, além da má distribuição da frota, ocasionando falta ou atraso nos compromissos dos usuários. 

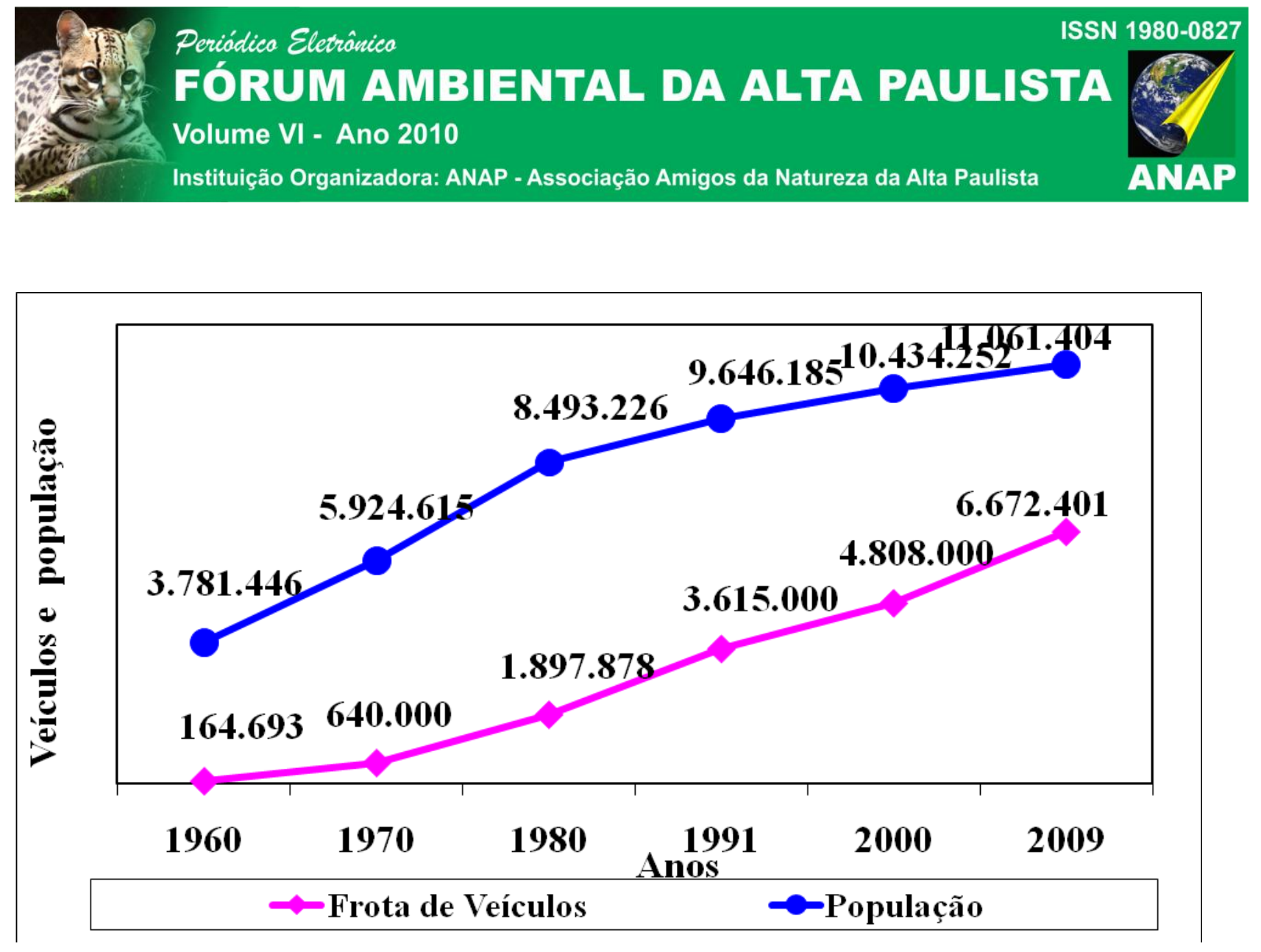

Gráfico 1 - Evolução da Frota de Veículos e da população: Município de São Paulo Fonte: CET, 2009b

\begin{abstract}
Nas grandes cidades, quanto maior a renda da população, maior o desejo das pessoas de usar o transporte individualmente. Muitas preferem viajar sozinhas por causa do conforto, da privacidade, flexibilidade e rapidez, diferentemente do que elas experimentariam se usassem o transporte público. Essa preferência pelo transporte individual aumenta de maneira significativa o número de veículos nas ruas. Muitos acreditam que os benefícios do transporte individual superam os do transporte público.O impacto do individualismo colabora grandemente para o aumento dos congestionamentos. Paulatinamente, mais e mais pessoas moram e trabalham em locais em que não há transporte público adequado. Com o fácil acesso à compra de um carro, é cada vez mais raro encontrar um carro com mais de um ocupante. Os dois fatores básicos que afetam o trânsito e causam congestionamento: excesso de veículos em horários específicos e acidentes ou ocorrências (pneu furado, falta de combustível, pistas bloqueadas para reparos, condições do tempo, etc.) que podem bloquear a pista (RESENDE; SOUSA, 2009).
\end{abstract}

Justificativas a parte, a realidade é que, ao migrar para o transporte em automóveis particulares, essa população contribui para a ocorrência de alguns fatores de risco para si: 
aumento da poluição do ar; aumento do número de veículos em circulação, ocasionando lentidão e congestionamentos e o aumento de acidentes de trânsito, pela posse e condução irresponsável de veículos

O volume de veículos que circulam em São Paulo associado às desfavoráveis condições de dispersão dos poluentes compromete a qualidade do ar da região metropolitana. A segurança e saúde da população estão também comprometidas pela ocorrência de congestionamentos e de acidentes provocados pelas más condições de circulação na cidade.

[...] Muitas vezes relaciona-se a questão de trânsito apenas à poluição atmosférica nas cidades, esquecendo-se que o impacto negativo do trânsito é mais abrangente, envolvendo a deterioração da qualidade de vida pelo stress vivido nos congestionamentos, pelo ruído gerado pelos veículos desregulados e pela insegurança que se vive diariamente na guerra que produz 2.400 mortos por ano. (SÃO PAULLO, 1996 p. 40)

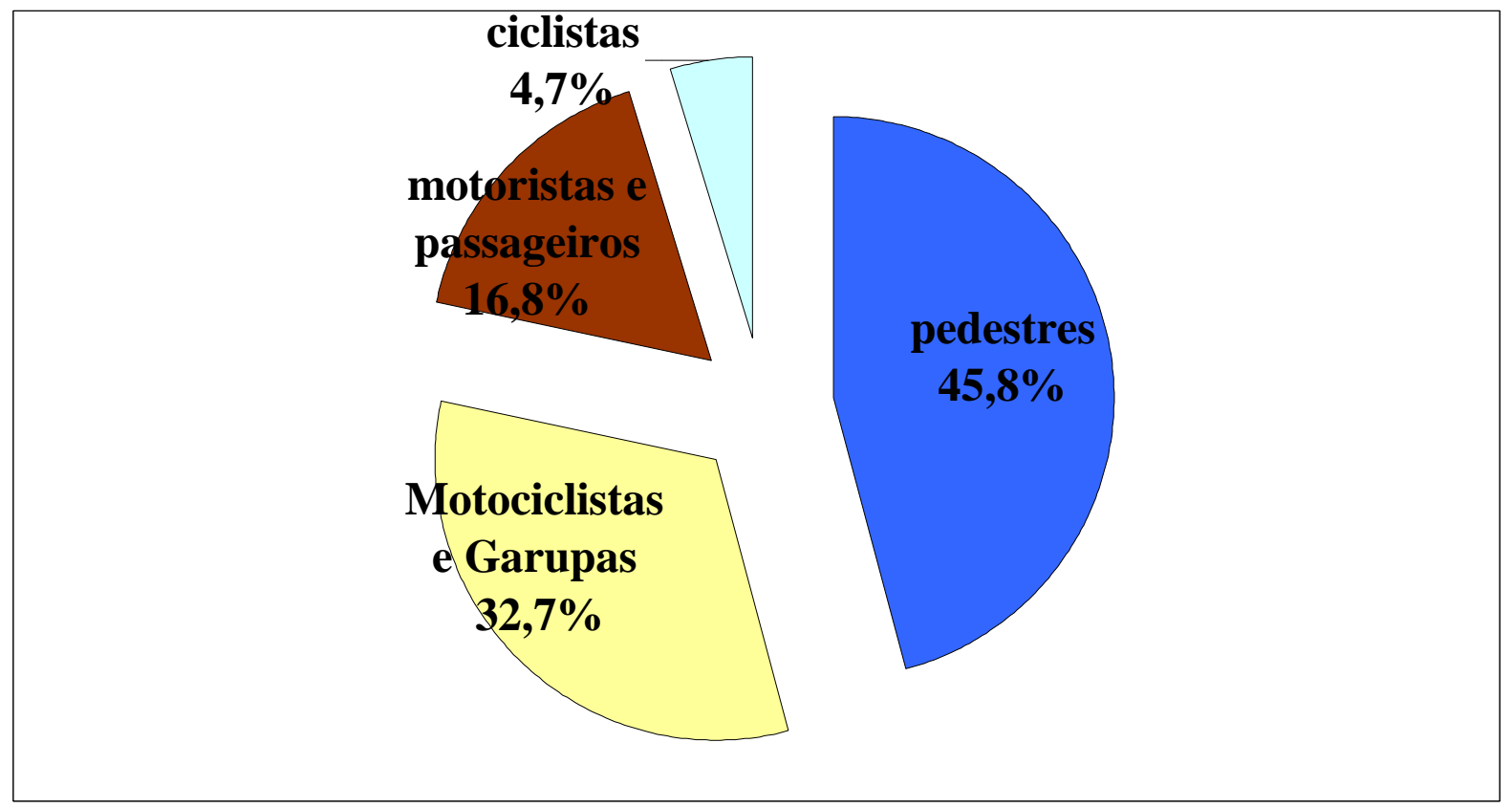

Gráfico 2 - Distribuição das mortes por todo de usuário de via

Fonte: CET, 2009b 
Em 2008, no município de São Paulo, ocorreram mais de 29.000 acidentes de trânsito e 1.463 óbitos, sendo que mais de $50 \%$ das vítimas fatais foram por casos de atropelamento. Segundo a OMS, um quarto das pessoas feridas em acidentes de trânsito fica com sequelas graves importantes, como perdas de órgãos ou problemas de locomoção (CET, 2008a)

Especialistas apontam que cerca de um quarto das pessoas feridas em acidentes de trânsito ficam com seqüelas importantes, como perda de movimentos, órgãos ou dificuldade de locomoção. As lesões decorrentes desse tipo de situação são de alto impacto e quase sempre vem acompanhadas de traumas graves. Todas as implicações são possíveis e, irreversíveis ou não, deixam sua marca de acidentes de trânsito, adquirem alguma deficiência permanente (GIOSTRI, 2009).

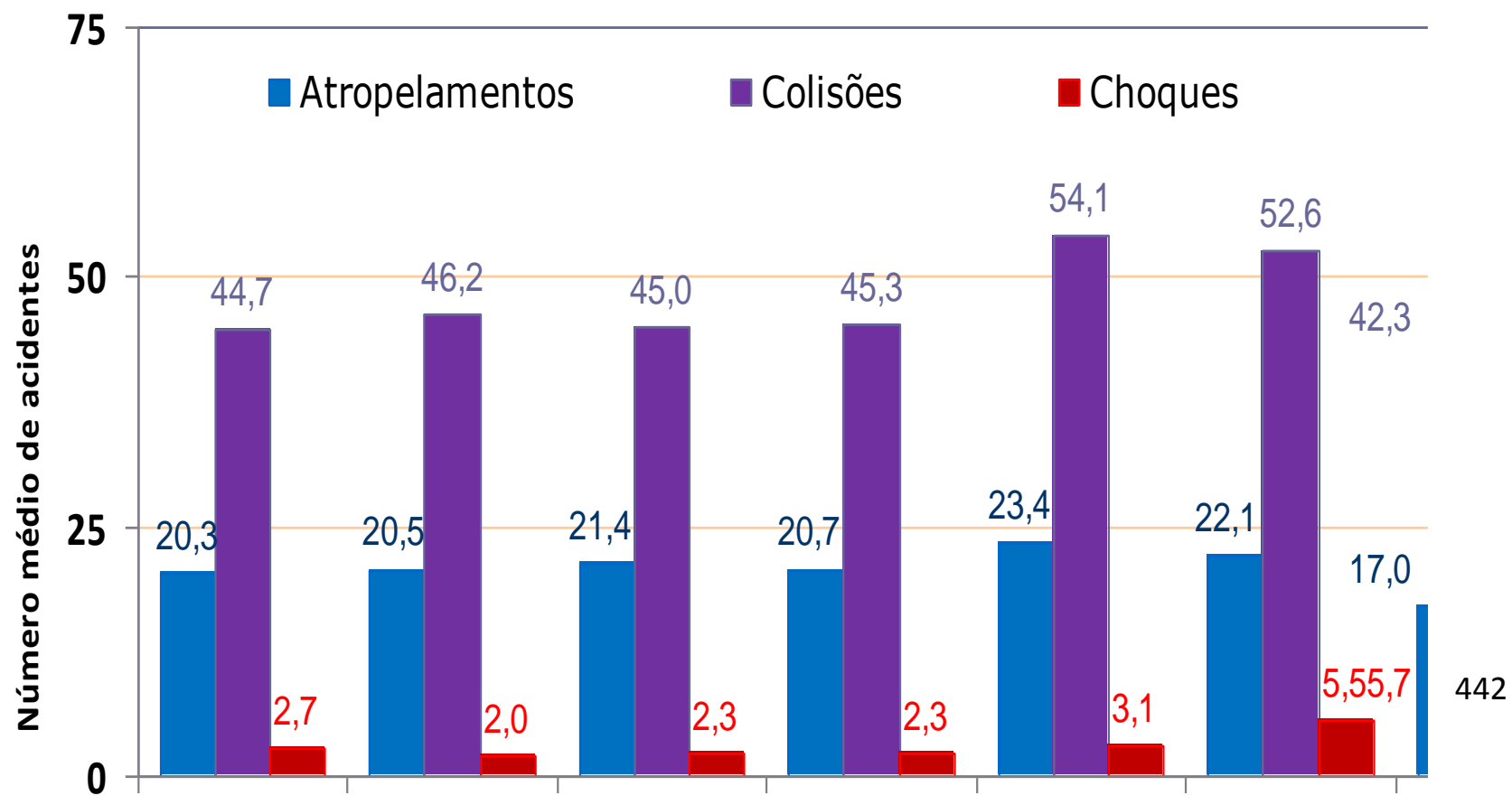


Gráfico 3 - Número médio de acidentes por tipo e dia da semana - Município de São Paulo, 2008.

Fonte: CET, 2008a

Atualmente, na cidade de São Paulo, segundo pesquisa realizada pela Fundação Dom Cabral, realizada entre 2004 e 2007, devido ao acúmulo de carros, os congestionamentos demoram cada vez mais a se dissipar e o resultado do aumento do número de automóveis em circulação são sucessivos recordes de engarrafamentos. Nos últimos doze anos, a média de lentidão no pico da manhã (entre 07h00 e 10h00 horas) aumentou 40\% e atingiram-se marcas como 260 quilômetros de congestionamento, e dia 9 de maio, quando um caminhão que carregava toras tombou no acesso à Rodovia Presidente Dutra e um derramamento de óleo paralisou a Avenida Giovanni Gronchi, no Morumbi, em São Paulo (foram registrados 266 quilômetros de lentidão). De 2006 para 2007, a velocidade média dos veículos nas ruas da capital caiu de 29 km/hora para 27 km/hora.

Os congestionamentos ocorrem quando a capacidade máxima de veículos por via é atingida ou quando há algum tipo de barreira (acidentes, buracos, desvios, etc.). Os prejuízos causados pelos congestionamentos são enormes: além das horas perdidas no deslocamento, há também um maior gasto com combustível e aumento da emissão de gases poluentes, com graves conseqüências para a saúde da população (MOVIMENTO NOSSA SÃO PAULO, 2009, p. 29).

Quanto à poluição do ar, São Paulo apresenta em algumas regiões alto índice de material particulado e monóxido de carbono, pela presença de um número elevado de veículos em circulação. Segundo Jacobi et al (1997, p. 6)

A qualidade do ar na Região Metropolitana de São Paulo é determinada por um complexo sistema de emissão de poluentes por fontes móveis (veículos automotores) e estacionárias. [...] A ocupação da frota é baixa, com média de 1,5 passageiros veículos, decorrentes, sobretudo, da carência e precariedade do sistema de transporte público, acentuada pela tendência cada vez mais comum de opção pelo transporte individual [...]. O trânsito intenso gerado pelo excesso de veículos nas vias públicas e pela subutilização da capacidade de transporte 
particular provoca a saturação do sistema viário, agrava os congestionamentos existentes e aumenta a emissão de poluentes de origem veicular. Os veículos são responsáveis por $90 \%$ da poluição.

Diante deste quadro, os órgãos responsáveis pela gestão do trânsito nos municípios, no caso da cidade de São Paulo, a Companhia de Engenharia de Tráfego, promovem medidas para a melhoria das condições e modernização do trânsito da cidade, como o monitoramento por câmeras que permitem o gerenciamento do trânsito, a alteração do tempo semafórico conforme o fluxo de veículos em um determinado cruzamento de vias, e a criação de bolsões de estacionamento próximo as estações do metrô, estimulando as pessoas ao uso deste meio coletivo.

Sendo assim, ações efetivas precisam ser constantemente tomadas, mas, muitas vezes, as necessidades quanto à mobilidade segura e ao cuidado com o meio ambiente, não dependem apenas dos órgãos gerenciadores de trânsito e transporte, mas de atitudes e posturas adotadas pelos cidadãos, moradores e usuários desta cidade.

A participação cidadã, que se mobiliza para exigir ações dos órgãos responsáveis sobre questões de trânsito, transportes e meio ambiente, é legítima, mas também, deve ser entendida como o cumprimento de medidas e a aquisição de hábitos que contribuam para o bem-estar de todos. Praticar cidadania ao circular pela cidade é medida emergencial para a melhoria das condições de circulação na cidade de São Paulo. E a educação para o trânsito pode se um grande instrumento para esta finalidade.

Cidadania é o processo histórico social que capacita a massa humana a forjar condições de consciência de organização e de elaboração de um projeto e de prática no sentido de deixar de ser massa e de passar a ser povo com sujeito histórico responsável pelo seu próprio destino (BOFF, 2000, p. 51).

A Companhia de Engenharia de Tráfego (CET) foi criada em 1976, tendo como missão sinalizar a cidade de São Paulo. Neste período a fiscalização e a educação de trânsito eram executadas por órgão do governo estadual. Aos poucos, o Estado delegou ao município poderes de órgão fiscalizador e esta área foi incorporada a Companhia. Nesta 
época, a cidade possuía 6 milhões de habitantes e uma frota de 1,4 milhões de veículos (CET, 2007).

Em 1980, mais uma área foi inserida ao escopo da Companhia, a área de educação de trânsito. A missão desta área foi o desenvolvimento de programas de educação para o trânsito, mediante a formação de professores, e comunidade geral, como motofretistas, pedestres em idade escolar, entre outros.

Atualmente, a Companhia de Engenharia de Tráfego de São Paulo possui três frentes de atuação para o gerenciamento e segurança do trânsito da cidade de São Paulo: Engenharia, Fiscalização e Educação de Trânsito.

Especificamente sobre a área de educação de trânsito da CET, esta é composta por três departamentos, independentes, cada qual com seu público-alvo e metodologia específica às características psicológicas e ao risco ao qual estão expostos no trânsito, conforme orientação das estatísticas de acidentes de trânsito na cidade. São atendidos mais de 200 mil munícipes por ano, sendo crianças e jovens, motociclistas, grupos de terceira idade, professores da rede escolar, entre outros (CET, 2008b).

Embora existam muitos desafios a serem vencidos, a educação para o trânsito tem uma missão a desempenhar, no sentido de propiciar a melhoria do meio ambiente local e planetário e a qualidade de vida.

\section{Agenda 21}

No Rio de Janeiro, aconteceu em 1992, a ECO 92 - Conferência das Nações Unidas sobre meio ambiente e desenvolvimento, onde 178 países assinaram um acordo de construção da agenda 21. Este acordo propõe como principal objetivo o desenvolvimento sustentável: economia viável, justiça social e equilíbrio ambiental.

Esta proposta de desenvolvimento reflete além da preservação do verde e animais em extinção, mas questões como consumo, habitação, pobreza, saúde, transportes. Propõe por meio dele, ações de planejamento integrado onde equilibra-se o desenvolvimento 
social, econômico, ambiental e tecnológico garantindo qualidade de vida e sobrevivência do planeta no século XXI.

Na construção da Agenda 21, há o envolvimento do poder público, privado e sociedade civil, sendo que a base é o princípio da sustentabilidade, a sustentabilidade socioambiental. Portanto, apesar de existirem níveis de implantação da Agenda 21, se não estiverem envolvidos estes três setores, não podemos considerar como agenda 21 .

O conceito de sustentabilidade considera este princípio como sistêmico incorporando ao seu significado, além da esfera ambiental, a econômica, social e cultural. Utilizar os recursos necessários ao desenvolvimento e manutenção dos povos atuais, sem esquecer quem vem nas gerações futuras, entendendo-se cada esfera em sua magnitude: ecologicamente correto, economicamente viável, socialmente justo e culturalmente aceito.

A agenda 21 brasileira propõe seis temas como centrais:

\section{Agricultura sustentável}

2. Cidades sustentáveis

3. Infraestrutura e integração regional

4. Gestão dos recursos naturais

5. Redução das desigualdades sociais

6. Ciência e Tecnologia para o desenvolvimento sustentável.

Os países signatários comprometem-se a produzir estratégias nacionais para 0 desenvolvimento sustentável e as autoridades locais devem estabelecer agendas locais, portanto o princípio de pensar o todo, pensar globalmente, mas as ações devem ser para o todo e para o local. Desta forma a comunidade global será um reflexo das tendências e escolhas feitas nas comunidades locais do mundo.

Segundo o Capitulo 28 (ONU, 1992), as autoridades locais: 


\begin{abstract}
são elas que constroem, operam e mantém a infra-estrutura econômica e ambiental e social, supervisionam os processos de planejamento, estabelecem políticas e regulamentos ambientais locais [...]. Como o nível de governo mais próximo, das pessoas, tem um papel vital na educação mobilização do público na promoção do desenvolvimento sustentável [...]. E em 1996 a maioria das autoridades locais de cada país deve ter realizado um processo de consulta com suas comunidades e alcançado um consenso sobre agenda 21 local.
\end{abstract}

O processo de Agenda 21 local envolve o desenvolvimento de políticas locais para 0 desenvolvimento sustentável e de construção de parcerias entre autoridades locais e outros setores para implantá-la. Há a necessidade de criar um sistema de gestão, planejamento e políticas públicas, envolvendo todos os setores da comunidade. Não é um ato informal, mas ações de planejamento da cidade.

\title{
A agenda 21 da cidade de São Paulo
}

O documento que resultou na Agenda 21 da cidade de São Paulo foi finalizado como tal, em 1996, após a realização de atividades desenvolvidas por grupos internos das Secretarias Municipais, grupos intersetoriais, entre outros. Foram organizados quatro grandes blocos temáticos: Desenvolvimento Urbano, Desenvolvimento Social, Qualidade Ambiental e Estrutura Econômica e Administrativa.

Dentro do tema Desenvolvimento Urbano, a discussão busca centrar-se na estruturação do espaço urbano do Município de São Paulo e suas formas diversas de ocupação. A subdivisão do tema contempla os itens: Uso e Ocupação do Solo, Habitação e Transportes.

Com relação ao item três, referente ao Trânsito e Transportes, o texto introdutório do capítulo, demonstra o peso desta variável no desenvolvimento e nas condições ambientais da cidade.

O volume de veículos que circulam em São Paulo associado às desfavoráveis condições de dispersão dos poluentes comprometem a qualidade do ar da região 
metropolitana. A segurança e saúde da população estão, também, comprometidas pela ocorrência de congestionamentos e de acidentes provocados pelas más condições de circulação na cidade (SÃO PAULO, 1996, p. 39).

Com relação ao sistema viário, o diagnóstico é que o mesmo não acompanhou a expansão da cidade nas mesmas proporções. O sistema de trilhos não passa de 500 km, o que dificulta a expansão para um transporte de massa, que não priorize o ônibus.

Segundo o documento:

Muita preocupação tem sido despertada pela contaminação e degradação ambiental a que o meio urbano está sujeito. Os efeitos adversos que os sistemas de transportes produzem na atmosfera das cidades têm sido alvo de atenção e de consenso geral: em muitas localidades o transporte seja não só o responsável pela contaminação da atmosfera, mas também, causador de prejuízos à paisagem e degradação do ambiente urbano. Essa visão parcial vê os problemas urbanos como conseqüência direta da ação dos sistemas de transporte e não como decorrência do processo geral de urbanização, que condiciona esse mesmo sistema de transporte (SÃO PAULO, 1996, p. 41).

Diz ainda o documento:

Muitas vezes relaciona-se a questão do trânsito apenas à poluição atmosférica das cidades, esquecendo-se que o impacto negativo do trânsito é mais abrangente, envolvendo a deterioração da qualidade de vida pelo stress vivido nos congestionamentos, pelo ruído gerado pelos veículos desregulados e pela insegurança que se vive diariamente na guerra que produz 2.400 mortos por anos (SÃO PAULLO, 1996, p. 42).

Dentro dos objetivos traçados para as ações de transportes encontram-se, pelo menos dois que retratam, de forma direta ou indiretamente, a importância da educação para o trânsito como meio para melhoria das condições de trânsito e meio ambiente :

- Aprimoramento dos procedimentos e técnicas de fiscalização e educação para o trânsito, tanto de motoristas e ciclistas quanto de pedestres.

- Desenvolvimento de comportamentos seguros no trânsito através da interação dos papéis de pedestre, ciclista e motorista, da prática da cidadania pela vivência em 
um espaço urbano, visando a redução dos acidentes de trânsito, a garantia de segurança aos usuários do sistema viário e a eliminação de comportamentos individuais nocivos ao conjunto dos cidadãos.

Sobre as ações propostas, o tópico seis, ressalta a Educação Ambiental no Transporte e no Trânsito. O item reforça a importância de desenvolver programas voltados à educação para o trânsito como os que a CET já desenvolve, com objetivo de melhorar as condições de segurança do usuário, através de ações pedagógicas com crianças e adolescentes. Este item estabelece que devem ser:

- Estimulados programas direcionados à educação voltada para o comportamento no trânsito, como os que a CET já desenvolve com o objetivo de melhorar as condições de segurança do usuário, através de ações pedagógicas com crianças e adolescentes: Para a faixa etária de 3 a 6 anos a estratégia de trabalho adotada é o teatro "Trânsito Contado em Contos" e "O Contador de Estórias". De 7 a 11 anos (alunos do 1ํㅡrau) é adotado o Espaço Vivencial de Trânsito - Unidade Móvel (uma cidade montada no pátio da escola). Para adolescentes é adotado o Espaço Vivencial de Trânsito - Unidades Fixas (espaço urbano simulado com instalações compostas de edificações e pistas contendo sinalização horizontal, vertical e semafórica, minicarros, vídeo games e vídeo clip). Foi também desenvolvido recentemente o "Role Play Game", um jogo que cria situações onde os jogadores devem buscar soluções para seus personagens. Outro programa desenvolvido "Travessia de Escolares", atua de modo a organizar o movimento de veículos e pedestres na área escolar, ampliando o trabalho pedagógico desenvolvido através dos programas de educação.

- Desenvolvidos trabalhos educativos conjunto com escolas e associações que atendem ao deficiente físico e mental. 
- Desenvolvidas campanhas educativas e de conscientização junto aos usuários do sistema viário, tais como "Use o Cinto de Segurança na Cidade", "Nunca Feche o Cruzamento", "Use Farol Baixo na Cidade".

- Desenvolvidos Programas de Mensagens Educativas: Aproveitar todos os espaços disponíveis nos impressos da CET, distribuídos como orientação aos motoristas, para mensagens educativas sobre a preservação do meio ambiente.

- Incluídos no programa dos cursos ministrados aos motoristas de ônibus e de táxi, matéria referente à conscientização sobre o impacto do sistema sobre o meio ambiente.

- Incluídas informações educativas sobre o meio ambiente nos espaços vivenciais de trânsito do Centro de Treinamento e Educação de Trânsito CETET.

Portanto, a educação para o trânsito foi contemplada na Agenda 21 de São Paulo como meio para a melhora nas condições de circulação da cidade, reforçando a importância, não apenas de investimentos em obras viários e veículos para transporte, mas também, a validade em disseminar comportamentos seguros e solidários para um trânsito e um ambiente mais equilibrado para todos.

A educação ambiental está prevista em vários níveis legais e na Agenda 21 da cidade de São Paulo são contempladas inclusive, com o caráter de melhoria da qualidade de vida da cidade e como meio de disseminação de educação ambiental, os programas de educação de trânsito da CET. Ações que buscam a conscientização para a vida em comunidade, que busquem melhorar a qualidade de vida da população do município de São Paulo, são imprescindíveis e urgentes, podendo realizar-se no âmbito familiar, mas principalmente, é importante que se desenvolvam em diferentes e múltiplos contextos, incluindo-se, neste caso, o contexto escolar, a fim de aproveitar o agrupamento diário 
realizado pela instituição escolar e a importância de transformar o professor em agente para a disseminação de conteúdos de educação ambiental, segurança e cidadania, como orientam as leis e a agenda 21 da cidade.

\section{Educação para o trânsito}

A Companhia de Engenharia de Tráfego (CET) foi criada em 1976, tendo como missão sinalizar a cidade de São Paulo. Neste período a fiscalização e a educação de trânsito eram executadas por órgão do governo estadual. Aos poucos, o Estado delegou ao município poderes de órgão fiscalizador e esta área foi incorporada a Companhia.

Em 1980 foi criado o Centro de Treinamento e Educação de Trânsito, CETET, com objetivo de tornar-se o espaço físico oficial da Companhia, onde estariam sediadas as ações de educação para o trânsito. Antes da criação do CETET, as atividades eram desenvolvidas pela assessoria de Comunicação Social.

Atualmente, a Companhia de Engenharia de Tráfego de São Paulo possui três frentes de atuação para o gerenciamento e segurança do trânsito da cidade de São Paulo: Engenharia, Fiscalização e Educação de Trânsito.

Especificamente sobre a área de educação de trânsito da CET, esta é composta por três departamentos, independentes, cada qual com seu público-alvo e metodologia específica às características psicológicas e ao risco ao qual estão expostos no trânsito, conforme orientação das estatísticas de acidentes de trânsito na cidade. São atendidos mais de 200 mil munícipes por ano, em programas de educação não-formal, sendo crianças e jovens, motociclistas, grupos de terceira idade, professores da rede escolar, entre outros.

Sobre a educação não-formal é importante ressaltar que a escola é um espaço importante para o processo educacional, mas não é o único. A educação não escolar sempre existiu, 
mas a partir do século XIX, a escolarização generalizou-se e o discurso pedagógico centrou-se mais nas unidades escolares. A educação formal e não-formal são intencionais, possuem objetivos claros de aprendizagem ou formação, podendo ser fora do marco institucional ou afastar-se dos procedimentos escolares convencionais, permanecendo à margem do organograma do sistema educacional graduado e hierarquizado.

[...] conjunto de meios e instituições que geram efeitos educacionais a partir de processos intencionais, metódicos e diferenciados, que contam com objetivos pedagógicos prévia e explicitamente definidos, desenvolvidos por agentes cujo papel educacional está institucional ou socialmente reconhecido, e que não faz parte do sistema educacional graduado ou que, fazendo parte deste, não constitui formas estritas e convencionalmente escolares (TRILLA, 1985, p. 19).

Ainda sobre a educação não-formal, Trilla (1985, p. 24) nos diz:

Os meios educacionais não-formais podem cobrir uma ampla gama de funções relacionadas com a educação permanente e com outras dimensões do processo educacional global, marginalizadas ou deficientemente assumidas pela instituição escolar.

Atualmente, são programas de educação não-formal, desenvolvidos pelo CETET:

- Público Infantil - Programas para a faixa etária de 4 a 6 anos. Escolas e instituições de educação maternal e infantil.

- Contador de Histórias - As aventuras de Zig: Por meio da história do cavalinho alado Zig, são trabalhados conceitos de segurança e cidadania no trânsito. Atividade para crianças até 6 anos. 


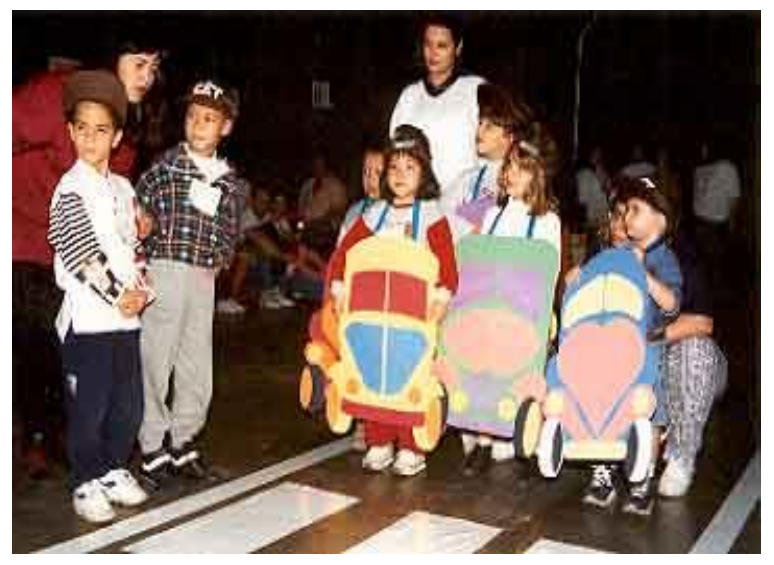

Figura 1 - Contador de história

Fonte: CET, 2009a

- Teatro de Fantoches - Festa na Floresta: Os bichos da floresta irão viver uma grande aventura, quando precisam sair da mata e enfrentar o agito da cidade a fim de comprar o presente de aniversário do Leo, o leão. Nesta aventura, aprendem a usar os signos da cidade, com o a faixa de segurança, calçada, semáforos, entre outros.

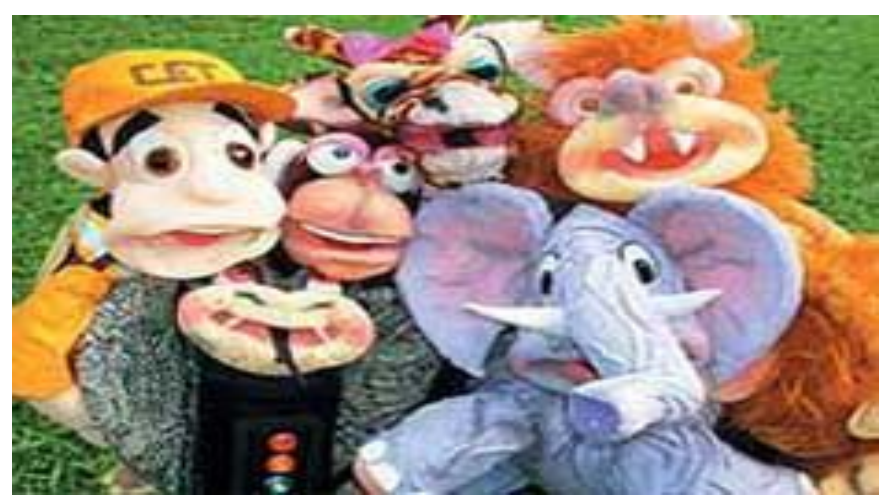

Figura 2 - Teatro de Fantoches - Festa na Floresta

Fonte: CET, 2009a 
- Ensino Fundamental I - Programa para faixa etária de 7 a 10 anos. Escolas e instituições do 1‥ ao 5․ ano.

- Espaço Vivencial de Trânsito Unidade Móvel: No ambiente escolar, utilizando o pátio ou a quadra de esportes da unidade escolar, é construída uma cidade, com painéis que simulam casas, comércios, serviços e carrinhos de espuma. $O$ ambiente de vias e calçadas e sinalizado com faixas adesivas brancas. Desenvolve-se, então, uma dramatização, na qual os alunos são levados a reflexão sobre comportamentos seguros e inseguros no trânsito e a forma mais segurança para a circulação.

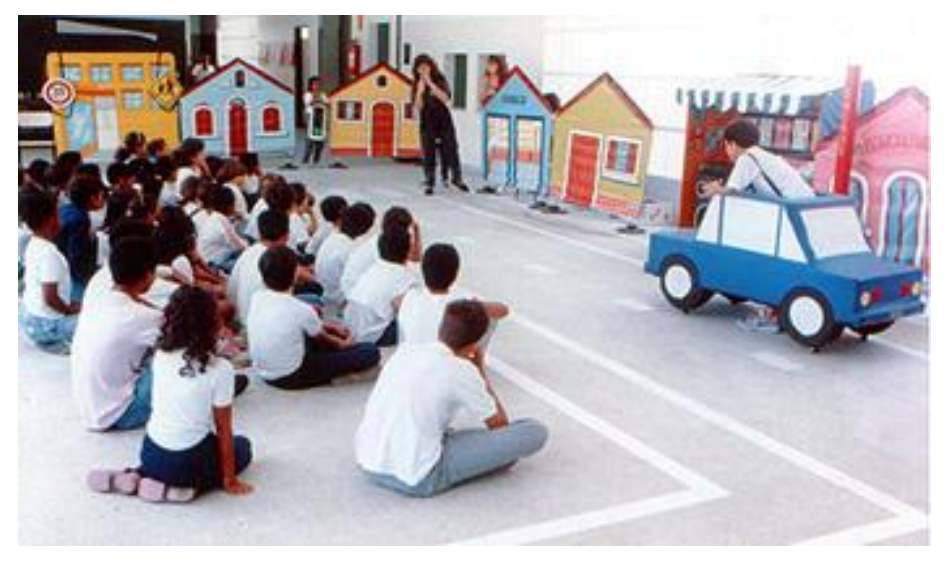

Figura 3 - Espaço Vivencial de Trânsito - Unidade Móvel Fonte: CET, 2009a

- Ensino Fundamental II - Programa para faixa etária de 11 a 17 anos. Escolas e instituições do $6^{\circ}$. ao 9․ ano.

- Espaço Vivencial de Trânsito Unidade Fixa: Local com pista sinalizada, veículos elétricos, videogame educativo e auditório. Neste local são recebidos cerca de 100 adolescentes por dia. Por meio de exposição dialogada e participação em 
atividades lúdicas os monitores do local promovem reflexão sobre trânsito e cidadania.

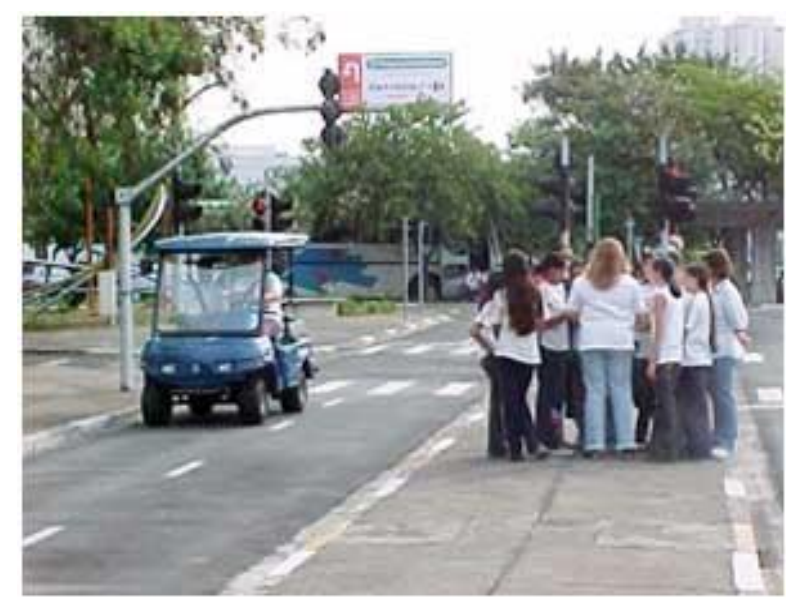

Figura 4 - Espaço Vivencial de Trânsito - Unidade Fixa

Fonte: CET, 2009a

- Ensino Médio - Programa para faixa etária de 15 a 21 anos. Escolas e instituições do $1^{\circ}$. ao $3^{\circ}$. ano, e cursos profissionalizantes do segundo grau.

- GP Segurança no Trânsito: Por meio de jogo educativo são trabalhados conceitos de direção defensiva, código de trânsito entre outros.

- Mídia e trânsito: Nesta atividade é feito um debate com os alunos, tendo como elemento de discussão as propagandas e os valores disseminados pela mídia. É feita reflexão sobre a propaganda e a formação de valores. 


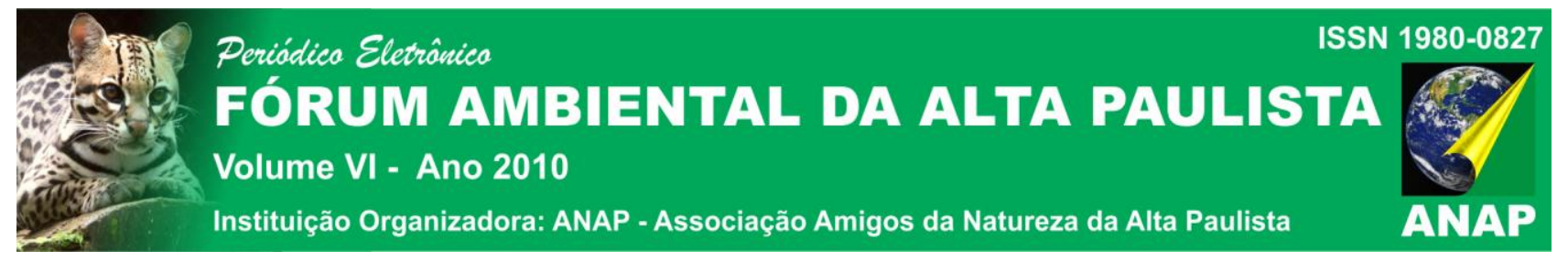

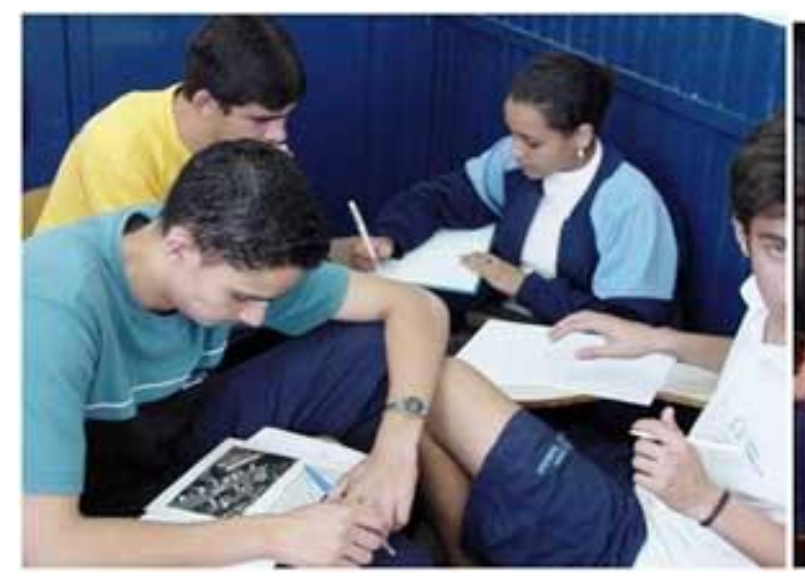

Figura 5 - Programa para o Ensino Médio - Mídia trânsito - Ensino Médio

Fonte: CET, 2009a

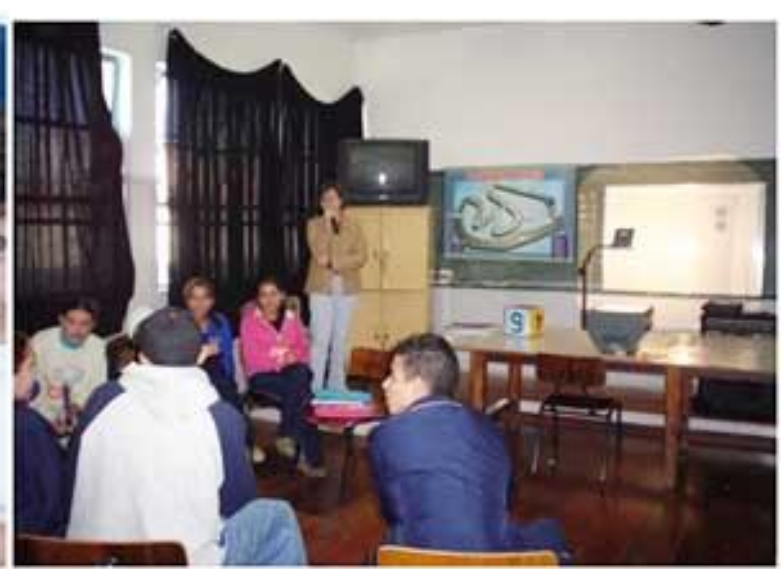

Figura 6 - GP Segurança no

Fonte: CET, 2009a

- Teatro Boto em trânsito: Tendo como inspiração a lenda amazonense sobre o Boto, é criado um ambiente urbano para a lenda, e os temas que permeiam este evento são as angústias e dilemas vividos pelos adolescentes, na fase de transição para a vida adulta.

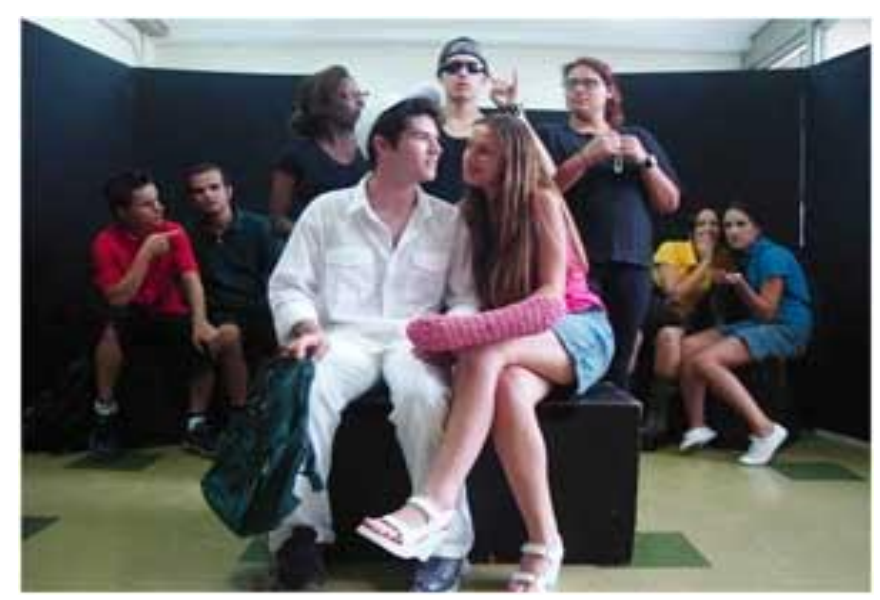

Figura 7 - Peça Teatral: O Boto em trânsito - Ensino Médio 
Fonte: CET, 2009a

Embora existam muitos desafios a serem vencidos, a educação para o trânsito tem uma missão a desempenhar: propiciar a melhoria do meio ambiente local e planetário e a qualidade de vida.

Portanto, a melhoria nas condições ambientais de segurança e saúde, na convivência e circulação na cidade de São Paulo, depende de ações de gerenciamento de trânsito e transporte, mas também, da educação disponibilizada em espaço formal e não-formal, disponibilizada para crianças e adolescentes.

\section{REFERÊNCIAS}

BRASIL. Constituição da República Federativa do Brasil, Brasília, DF: 1988.

. Lei no 9.503, de 23 de setembro de 1997. Código de Trânsito Brasileiro. Brasília, 1997.

Lei Estadual № 12.780, de 30 de novembro de 2007. Institui a Política Estadual de Educação

Ambiental de São Paulo. São Paulo: DOE, 01 dez. 2007. Disponível em: < http://www.cetesb.sp.gov.br/licenciamentoo/legislacao/estadual/leis/2007_Lei_Est_12780.pdf>. Acesso em: 30 mar. 2010.

BRITO, Ana Claudia, et al. Fazendo escola: capacitação de professores. Boletim Técnico, n. 45 , São Paulo: CET, 2009.

BOFF, Leonardo. Depois de 500 anos: que Brasil queremos? Petrópolis, RJ: Vozes, 2000.

. Relatório de Gestão 2005-2006. São Paulo: Prefeitura Municipal de São Paulo, CET, 2007.

Fatos e dados estatísticos. São Paulo: CET. 2008a.

Relatório Interno de Educação para o Trânsito. São Paulo: CET, 2008b.

Site institucional. São Paulo: CET, 2009a. Disponível em <www.cetsp.com.br>. Acesso em: 28 mar. 2010.

. Relatório: Mortes no trânsito do município de São Paulo. São Paulo: CET, 2009b.

FREIRE, Paulo. Conscientização. São Paulo: Moraes, 1980.

GIL, Antonio Carlos. Metodologia do Ensino Superior. São Paulo: Atlas, 1999.

GIOSTRI, Gianne. Acidentes de trânsito provocam seqüelas irreversíveis. Bem Paraná, 2009. Disponível: $<$ http://www.bemparana.com.br/index.php?n=81895\&t=acidentes-de-transito-provocam-sequelasirreversiveis>. Acesso em: 07 nov. 2009. Não paginado. 
IBGE. Cidades@. São Paulo, 2009 Disponível em: shttp://www.ibge.gov.br/cidadesat/topwindow.htm?1>. Acesso em: 20 abr. 2010.

JACOBI, Pedro. Cidade e meio ambiente: percepções e práticas em São Paulo. São Paulo: Annablume, 2000.

JACOBI, Pedro et al. Poluicão do ar em São Paulo e resposta da ação pública. Cadernos CEDEC, n. 60, São Paulo, CEDEC, 1997.

MOVIMENTO NOSSA SÃO PAULO. Indicadores Básicos da Cidade de São Paulo. São Paulo, Dumpa Desing, 2009.

ORGANIZAÇÃO DAS NAÇÕES UNIDAS (ONU). Agenda 21 da Conferência das Nações Unidas sobre Meio Ambiente e Desenvolvimento: capítulo 28, iniciativas das autoridades locais em apoio à Agenda 21. Rio de Janeiro, $1992 . \quad$ Disponível em: $<$ http://www.mma.gov.br/sitio/index.php?ido=conteudo.monta\&idEstrutura=18\&idConteudo=871>. Acesso em: 02 mai. 2010.

PIAGET, Jean. A epistemologia genética. Petrópolis: Vozes, 1971.

RESENDE, Paulo Tarso Vilela; SOUSA, Paulo Renato. Mobilidade Urbana nas grandes cidades brasileiras: um estudo sobre impactos do congestionamento. Caderno de Idéias. Minas Gerais, Nova Lima: Fundação Dom Cabral, 2009. Disponível em: <http://acervo.ci.fdc.org.br/AcervoDigital/Cadernos\%20de\%20ldéias/2009/CI0910.pdf >. Acesso em: 05 abr. 2010.

RODRIGUES, Angélica Cosenza. A Educação Ambiental e o fazer interdisciplinar na escola. Juiz de Fora: Junqueira e Marin Editores, 2008.

SÃO PAULO. Agenda 21 local: o compromisso do município de São Paulo. Grupo de trabalho Intersetorial. Aprovada pelo CADES. Resolução n. 17/96. São Paulo: DOM. 06 ago. 1996.

SILVA, Antonio Luiz. Programa de Educação não-formal para utilização de eletricidade: uma experiência em comunidades carentes (2003-2004). Dissertação (Mestrado) - Programa de Educação, Arte e História da Cultura. Universidade Presbiteriana Mackenzie, São Paulo, 2005.

TRILLA, Jaume. Profissão Educador Social. Porto Alegre: Artmed, 2003. p. 11-47.

TOLENTINO, Nereide. Na escola, professores: o que é trânsito. 2006. Disponível em: $\leq$ sww.educacaotransito.pr.gov.br/module/conteudo/conteudo.php:conteudo=84>. Acesso em: 02 mai. 2010. Não paginado.

VASCONCELOS, Eduardo. O que é trânsito. Coleção Primeiros Passos. São Paulo: Ed. Brasiliense, 1985. VYGOTSKY, Lev Semenovich. A formação social da mente. São Paulo: Martins Fontes, 1991. 